\title{
Comienzo de los alumnos en la Universidad: autorregulación y primeros resultados
}

José Manuel Navarro Jover

Universitat Politècnica de València (jnavar@dig.upv.es)

\begin{abstract}
In this work, the level of self-regulation for academic learning at the University has been evaluated at the beginning of the course, and related to other academic variables. It has been observed that the students with the greatest capacity for self-regulation are the ones who choose to study the degree as first options. The qualification obtained in the first act of evaluation of the course was not related to the self-regulation capacity or to the access note. However, it was correlated with the class attendance rate $(r=0.42 ; p<0.05)$. All this highlights the importance of class attendance, at least in subjects that require the development of spatial vision ability, and especially in this context of adaptation and innovation that entails the beginning of university studies.
\end{abstract}

Keywords: self-regulation, learning, academic performance, access, attendance, University, preference, questionnaire.

\footnotetext{
Resumen

En este trabajo, al principio de curso se ha evaluado el nivel de autorregulación para el aprendizaje académico en la Universidad, y se ha puesto en relación con otras variables de tipo académico. Se ha observado que los estudiantes con mayor capacidad de autorregulación son los que eligen estudiar la titulación en primeras opciones. La calificación obtenida en el primer acto de evaluación del curso no resultó relacionada con la capacidad de autorregulación ni con la nota de acceso. Sin embargo, sí resultó correlacionada $(r=0,42 ; p<0,05)$ con la tasa de asistencia a clase. Todo esto resalta la importancia de la asistencia a clase, al menos en asignaturas que requieren el desarrollo de la habilidad de visión espacial, y sobre todo en este contexto de adaptación e innovación que conlleva el comienzo de los estudios universitarios.
}

Palabras clave: autorregulación, aprendizaje, rendimiento académico, acceso, asistencia, Universidad, , preferencia, cuestionario.

\section{Introducción}

La autorregulación del aprendizaje es un constructo de gran relevancia y vigencia en el ámbito educativo. Consiste en la organización deliberada de actividades cognitivas, conductuales y ambientales que conducen al éxito en el aprendizaje (Hernández y Camargo, 
2017). La autorregulación implica una serie de estrategias de aprendizaje que los alumnos ponen en marcha cuando trabajan, para alcanzar las metas que se han fijado a sí mismos (Panadero y Alonso-Tapia, 2014).

El presente trabajo forma parte de una investigación que se está llevando a cabo en la Universitat Politècnica de València con los alumnos de dos subgrupos de la asignatura Representación Gráfica en la Ingeniería, troncal de primer curso del grado en Ingeniería Agroalimentaria y del Medio Rural. En la misma se pretende estimular la capacidad de autorregulación de los alumnos, mediante la realización, a lo largo del curso, de unas actividades de autorrealimentación por parte de los mismos.

En los últimos años se viene observando por parte de los profesores de la asignatura que los alumnos no dedican tiempo a la misma hasta que no llega el momento de realizar el primer acto importante de evaluación, que es el primer examen parcial. Este hecho resulta especialmente perjudicial para los intereses académicos de los alumnos, ya que se trata de una asignatura eminentemente práctica y que requiere un ejercicio y desarrollo continuo de la capacidad de visión espacial, por lo que exige un trabajo continuado que, semana tras semana, desarrolla una gimnástica funcional cerebral. Cuando no se produce este proceso, el alumno obtiene malos resultados desde el principio y, sobre todo, puede quedar descolgado del ritmo de la asignatura. Sería por tanto deseable que los alumnos tomaran conciencia de estos hechos y consiguieran autorregularse para alcanzar estos objetivos. Por ello, y teniendo en cuenta el creciente interés que despierta la realimentación y su relación con el aprendizaje autorregulado (Gallego et al., 2017; García-Jiménez et al., 2015; Garello y Rinaudo, 2013; Labuhn et al., 2010; Llorens et al., 2016), se ha diseñado una actividad de autorrealimentación, a través de la cual es el propio alumno el que se auto diagnostica y se proporciona realimentación. De esta forma el estudiante podría llevar a cabo una comparación entre su objetivo inicial y su rendimiento, y promover procesos de reflexión, revisión y optimización de su aprendizaje (Garello y Rinaudo, 2013), mejorando su capacidad de autorregulación. En este trabajo se recogen y analizan los resultados preliminares de este planteamiento, a partir de los datos recogidos en las primeras semanas del curso, referentes a la capacidad de autorregulación de los alumnos y a los primeros resultados académicos.

\section{Objetivos}

El objetivo de este trabajo es evaluar y analizar el nivel de autorregulación de los alumnos al comienzo de la asignatura, así como su análisis y puesta en relación con algunas variables de tipo académico (asistencia a clase, nota del primer acto de evaluación del curso, nota de acceso a la universidad, y orden de preferencia en la elección de los estudios).

Las hipótesis de partida son:

a) Los alumnos que tienen mayor capacidad de autorregulación tendrán mayor nota de acceso a la Universidad

b) Los alumnos que tienen mayor capacidad de autorregulación obtendrán mayor nota en el primer acto de evaluación del curso 
c) El orden de preferencia en la elección de los estudios está relacionado con la capacidad de autorregulación. Los alumnos que eligen en primeras opciones su titulación, tienen mayor autorregulación

d) Los alumnos que asisten más a clase obtienen mejor notas en la primer acto de evaluación del curso

e) No existen diferencias por sexo en la capacidad de autorregulación

f) No existen diferencias por sexo en la nota de acceso a la Universidad

g) No existen diferencias por grupo en la capacidad de autorregulación

h) No existen diferencias por grupo en la nota de acceso a la Universidad

Las variables que se consideran son:

- Sexo

- Grupo de clase $(G R)$

- Nota de acceso a la Universidad (Nacc): numérica 0 a 14

- Orden de preferencia de elección de la titulación (Opción): $1^{\mathrm{a}}, 2^{\mathrm{a}}, 3^{\mathrm{a}}, 4^{\mathrm{a}}, \geq 5^{\mathrm{a}}$

- Puntuación obtenida en el cuestionario de autorregulación (AR): 20 a 100

- Puntuaciones obtenidas en cada factor componente del cuestionario de autorregulación $(I, I I, I I I, I V)$

- Asist: Portcentaje de asistencia a clase las primeras 3 semanas de curso (hasta la realización del primer acto de evaluación)

- CP1: Nota obtenida en el primer acto de evaluación (realizado la cuarta semana de curso)

\section{Desarrollo de la innovación}

El trabajo se ha llevado a cabo en la Escuela Técnica Superior de Ingeniería Agronómica y del Medio Natural de la Universitat Politècnica de València, con los alumnos de dos subgrupos (B1 y B2) de prácticas de la asignatura Representación Gráfica en la Ingeniería, troncal de primer curso, segundo semestre en el curso académico 2018/19. La población participante en el mismo es de 36 alumnos.

Las variables de asistencia, calificación del primer acto de evaluación, sexo y grupo se obtienen de los registros del profesor. Para medir la capacidad de autorregulación de los alumnos, se pasó al comienzo de la asignatura el cuestionario sobre autorregulación para el aprendizaje académico en la Universidad, de Torre (2007). Consta de 20 ítems en escala Likert con cinco niveles (desde "nada que ver conmigo" -1-, ..., hasta "yo soy así" - 5-). Este cuestionario (Tabla 1) recoge información sobre cuatro factores o componentes ligados con aspectos relacionados con la autorregulación académica: (I) conciencia metacognitiva activa, (II) control y verificación, (III) esfuerzo diario en la realización de las tareas y (IV) procesamiento activo durante las clases. 
Tabla 1. Cuestionario de autorregulación para el aprendizaje académico en la Universidad

\begin{tabular}{|c|c|c|}
\hline & Cuestión & Factor \\
\hline 1 & Para mí, estudiar requiere tiempo, planificación y esfuerzo & II \\
\hline 2 & $\begin{array}{l}\text { Cuando estoy estudiando algo, me digo interiormente cómo tengo que } \\
\text { hacerlo }\end{array}$ & II \\
\hline 3 & Sé con precisión qué es lo que pretendo al estudiar cada asignatura & I \\
\hline 4 & Yo creo que la inteligencia es una capacidad modificable y mejorable & II \\
\hline 5 & $\begin{array}{l}\text { Por mi experiencia personal, veo que mi esfuerzo e interés por aprender se } \\
\text { mantienen a pesar de las dificultades que encuentro. }\end{array}$ & III \\
\hline 6 & $\begin{array}{l}\text { Cuando me pongo a estudiar tengo claro cuándo y por qué debo estudiar de } \\
\text { una manera y cuándo y por qué debo utilizar una estrategia distinta }\end{array}$ & I \\
\hline 7 & Tengo confianza en mis estrategias y modos de aprender & I \\
\hline 8 & $\begin{array}{l}\text { Si me encuentro con dificultades cuando estoy estudiando, pongo más } \\
\text { esfuerzo o cambio la forma de estudiar o ambas cosas a la vez }\end{array}$ & I \\
\hline 9 & $\begin{array}{l}\text { Después de las clases, ya en casa, reviso mis apuntes para asegurarme que } \\
\text { entiendo la información y que todo está en orden }\end{array}$ & III \\
\hline 10 & Estoy siempre al día en mis trabajos y tareas de clase & III \\
\hline 11 & Yo creo que tengo fuerza de voluntad para ponerme a estudiar & III \\
\hline 12 & $\begin{array}{l}\text { Cuando estoy estudiando una asignatura, trato de identificar las cosas y los } \\
\text { conceptos que no comprendo bien }\end{array}$ & II \\
\hline 13 & $\begin{array}{l}\text { No siempre utilizo los mismos procedimientos para estudiar y aprender; sé } \\
\text { cambiar de estrategia }\end{array}$ & I \\
\hline 14 & $\begin{array}{l}\text { Según voy estudiando, soy consciente de si voy cumpliendo o no los } \\
\text { objetivos que me he propuesto }\end{array}$ & II \\
\hline 15 & $\begin{array}{l}\text { Cuando estoy leyendo, me detengo de vez en cuando y, mentalmente, reviso } \\
\text { lo que se está diciendo }\end{array}$ & II \\
\hline 16 & $\begin{array}{l}\text { Durante la clase, verifico con frecuencia si estoy entendiendo lo que el } \\
\text { profesor está explicando }\end{array}$ & IV \\
\hline 17 & $\begin{array}{l}\text { Los obstáculos que voy encontrando, sea en clase o cuando estoy } \\
\text { estudiando, más que desanimarme son un estímulo para mí }\end{array}$ & IV \\
\hline 18 & $\begin{array}{l}\text { Cuando estoy estudiando, me animo a mí mismo interiormente para } \\
\text { mantener el esfuerzo }\end{array}$ & II \\
\hline 19 & En clase estoy atento a mis propios pensamientos sobre lo que se explica & IV \\
\hline 20 & $\begin{array}{l}\text { Tengo mis propios criterios sobre cómo hay que estudiar y al estudiar me } \\
\text { guío por ellos }\end{array}$ & I \\
\hline
\end{tabular}

Al cuestionario se le añadieron tres preguntas para obtener los datos restantes de cada alumno: nota de acceso a la Universidad (Nacc) y su opción de preferencia en la elección de la titulación (Opción).

Para el análisis estadístico de los datos se utilizó el paquete estadístico Statgraphics Centurion XXVII. Aparte del análisis descriptivo, se realiza análisis cuantitativo. Se lleva a cabo un análisis correlacional para medir cómo interactúan y el grado de relación entre las variables 
numéricas descritas: Autorregulación (AR total y sus factores componentes), Nacc, Asist y $C P 1$. Mediante análisis de varianza se evalúa la posible relación entre la opción en que se eligieron los estudios y la autorregulación.

Se realiza una comparación de medias para ver si tiene influencia el sexo o el grupo en otras variables cuantitativas $(A R, C P 1, N a c c)$. Y sendos test Chi-cuadrado para estudiar la relación de la variable Opción (variable categórica) con el sexo y con el grupo.

En la Figura 1 se representan las variables que intervienen en el estudio así como las relaciones analizadas entre las mismas, así como las distintas hipótesis consideradas.

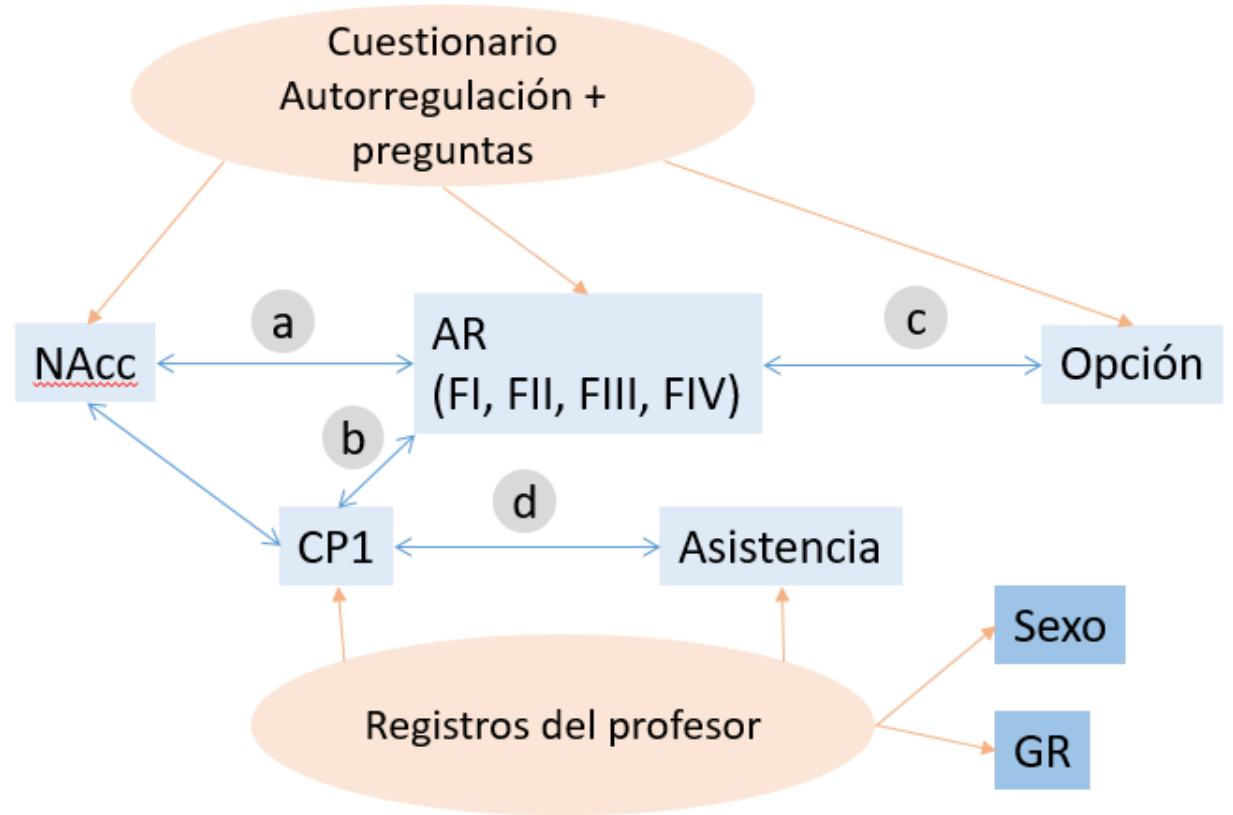

Fig. 1 Variables que intervienen en el estudio y las principales hipótesis consideradas

\section{Resultados}

La puntuación media obtenida por los alumnos en el test de Autorregulación es 71,28, ligeramente inferior al valor medio obtenido por Torre (2006), con una desviación similar $(8,7)$. Se observa en la Figura 2 el histograma. 


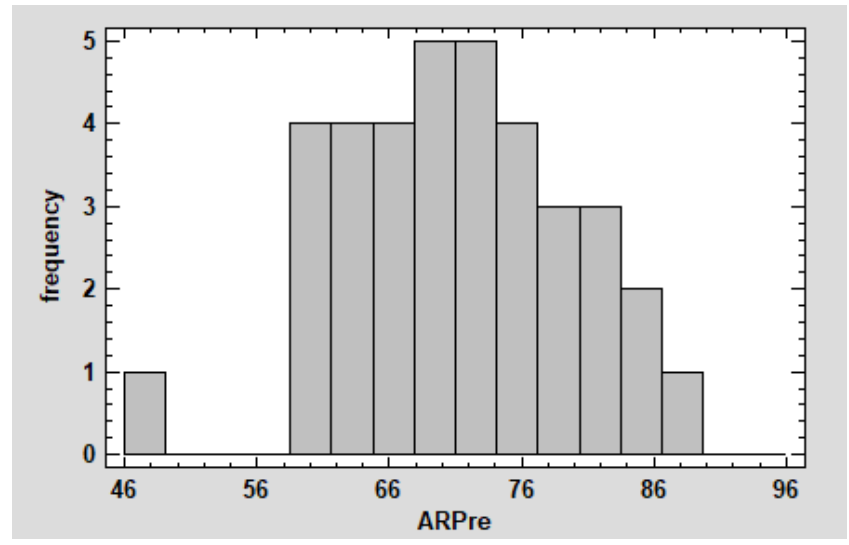

Fig. 2 Histograma de la variable Autorregulación

No se observan diferencias por sexo en la variable capacidad de autorregulación. Tampoco por grupo. De la misma forma, la variable Opción tampoco resulta estar relacionada con el sexo ni con el grupo.

En cuanto a los factores componentes de la autorregulación, el factor en que más puntuación han obtenido los alumnos (en promedio para todos los alumnos y todas las preguntas del factor) es el II Control y verificación (4,1 puntos en la escala liker de 1 a 5), mientras que el menos puntuado es el factor III Esfuerzo diario en la realización de las tareas (3,1 puntos). Este punto corrobora el hecho observado y comentado en la introducción, de que los alumnos no dedican tiempo y esfuerzo diario a la asignatura desde el principio de la misma.

Se ha observado una diferencia significativa entre ambos grupos en la Nota media de acceso a la Universidad (Figura 3). Los alumnos del grupo 1 accedieron a la Universidad con nota superior (media 9,31) a los del grupo 2 (media 7,38); $\mathrm{p}<0,05$. Esto puede ser debido a que los alumnos se matriculan por orden de nota de acceso, y por alguna razón, los alumnos que se matriculan primero suelen elegir el grupo 1. La razón subyacente podría residir en preferencias de horarios, pero más probablemente se deba simplemente a que en el formulario de automatrícula, en la casilla desplegable "grupo" aparece por defecto grupo 1, y los alumnos aceptan esta opción sin cambiarla en caso de que les sean indiferentes ambos horarios. 


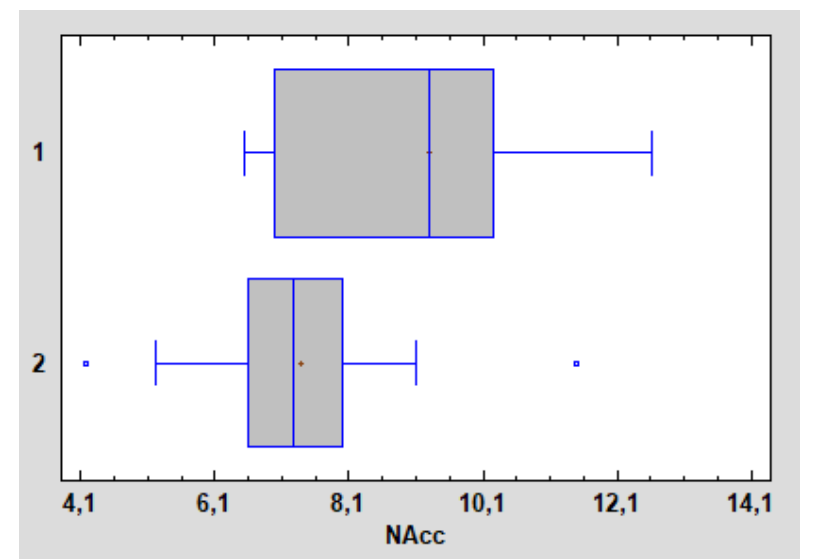

Fig. 3 Diagrama de cajas de la nota de acceso para cada grupo de clase

No ha habido diferencias en la asistencia a clase ni en la nota CP1 por grupo ni por sexo.

Se ha observado una relación positiva, aunque no significativa $(\mathrm{r}=0,30 ; \mathrm{p}=0,08)$, entre la puntuación en el cuestionario de Autorregulación y la nota de acceso a la Universidad. Por tanto queda desechada la primera hipótesis. No obstante sí que resulta importante y significativa la relación positiva entre la nota de acceso y uno de los factores componentes de la autorregulación, el factor III (esfuerzo diario en la realización de las tareas) $(\mathrm{r}=0,38 ; \mathrm{p}$ $<0,05$ ). Los alumnos que manifiestan tener por costumbre poner más empeño y esfuerzo en el trabajo diario son los que obtienen mayor nota de acceso.

No se ha encontrado relación entre la autorregulación y la nota del primer acto de evaluación del curso, lo cual permite desechar también la segunda hipótesis. Tampoco hay relación entre Nacc y CP1.

La tercera hipótesis queda confirmada: como resultado del análisis de varianza se desprende que existen diferencias en la puntuación de autorregulación en función del orden de preferencia en la elección de la titulación por el alumno. Las medias de AR resultan significativamente inferiores para los valores de Opción $3^{\mathrm{a}}, 4^{\mathrm{a}}$ y $5^{\mathrm{a}}$. Es decir, los alumnos que obtienen menor puntuación en la capacidad de autorregulación eligen la titulación en opciones $3^{\circ}, 4^{\mathrm{a}}$ y $5^{\mathrm{a}}$ o más.

Se ha observado una relación significativa entre la asistencia (Asist) y la nota obtenida en el primer caso práctico $(\mathrm{CP} 1)(\mathrm{r}=0,42 ; \mathrm{p}<0,05)$. Los alumnos que asisten más a clase obtienen mayor nota en el primer caso práctico, confirmando la cuarta hipótesis.

\section{Conclusiones}

En esta primera etapa del estudio global del que forma parte este trabajo se ha evaluado la autorregulación académica de los alumnos al comienzo de la asignatura, y se ha puesto en relación con otras variables disponibles en este momento: tasa de asistencia, nota del primer acto de evaluación, nota de acceso y opción en que se eligió cursar la titulación. 
La excelencia (notas elevadas de acceso a la Universidad) tiene que ver con los enfoques de aprendizaje profundos (Gargallo et al., 2012), sin embargo no se ha podido probar su relación (aunque por poco, $\mathrm{r}=0.3 ; \mathrm{p}=0,08$ ) con la autorregulación. Cabe destacar la relación obtenida entre el nivel de autorregulación y la opción en que los alumnos eligen los estudios: los alumnos con más capacidad de autorregulación han elegido la titulación opciones más tempranas. Posiblemente sea debido a la estrecha relación de la autorregulación con los estilos de aprendizaje más profundos, y por tanto con un alto grado de madurez emocional, personal y académica, según indican Alonzo et al. (2016).

En el contexto de esta asignatura, es de suma importancia concienciar o al menos informar a los alumnos de la importancia, desde el principio, de la asistencia a clase de cara a su éxito académico, según queda demostrado por su relación con la nota obtenida en el primer caso práctico, por la baja puntuación obtenida en el factor III, y corroborado por la impresión y opinión del profesorado implicado. Tanto a clases prácticas como teóricas, ya que debido al carácter eminente práctico de esta asignatura, es difícil establecer una distinción entre ambas. Los conocimientos teóricos son muy relevantes y a la vez cortos en densidad y en tiempo, de forma que las clases teóricas son también eminentemente prácticas y plagadas de ejemplos y ejercicios concretos de reafirmación de contenidos teóricos.

Aunque no se ha encontrado relación entre la Autorregulación y el resultado del primer acto de evaluación, la relación entre autorregulación y rendimiento académico global (al final del curso) sigue siendo la hipótesis de partida y motivadora del estudio global, en el cual se pretende durante el curso fomentar y aumentar la capacidad de autorregulación de los alumnos (que será estimada de nuevo al final del curso), a través de la realización de actividades concretas de autorrealimentación. De esta forma se pretende que los alumnos desde los primeros días dediquen tiempo y esfuerzo para progresar en la asignatura evitando el abandono o los malos resultados. Esta falta de relación de la nota CP1 con la autorregulación y también con la nota de acceso, puede deberse al cambio que supone el ingreso en la Universidad, etapa en la que el alumnado precisa un importante proceso de adaptación a los nuevos métodos y sistemas a los que se enfrenta el primer año. De manera que el bagaje con el que llega a la Universidad no es un factor suficiente o determinante para un buen comienzo.

\section{Referencias}

ALONZO, D.L., VALENCIA, M.C., VARGAS, J., BOLIVAR, N.J. y GARCIA, M.J. (2016). "Los estilos de aprendizaje en la formación integral de los estudiantes" en Boletín Redipe, vol. 5, issue 4, p. 109-114.

https://revista.redipe.org/index.php/1/article/view/105 [Consulta: 20 marzo de 2019]

GALlEGO, B. QUESADA, V. GÓMEZ, M.A. y CUBERO, J. (2017). "La evaluación y retroalimentación electrónica entre iguales para la autorregulación y el aprendizaje estratégico en la universidad: la percepción del alumnado" en REDU. Revista de Docencia Universitaria, vol 15, issue 1, p. 127-146.

(c)) EY-NC-ND 2019, Universitat Politècnica de València 
$<$ https://riunet.upv.es/bitstream/handle/10251/85079/5991-28452-1PB.pdf?sequence $=1 \&$ isAllowed $=\mathrm{y}>$ [Consulta: 10 de enero de 2019]

GARCÍA-JIMÉNEZ, E., GALLEGO-NOCHE, B. y GÓMEZ-RUÍZ, M.A. (2015). “ Feedback and Self-Regulated Learning: How Feedback Can Contribute to Increase Students' Autonomy as Learners" en Peris-Ortiz M., Merigó Lindahl J. (eds) Sustainable Learning in Higher Education, Innovation, Technology, and Knowledge Managment. Springer, Cham.

https://link.springer.com/chapter/10.1007\%2F978-3-319-10804-9 9 [Consulta: 20 de marzo de 2019]

GARELLO, M. V. y RINAUDO, M. C. (2013). "Autorregulación del aprendizaje, feedback y transferencia de conocimiento. Investigación de diseño con estudiantes universitarios" en Revista Electrónica de Investigación Educativa, vol. 15, issue 2, p. 131-147.

http://redie.uabc.mx/vol15no2/contenido-garellorinaudo.html [Consulta : 8 de noviembre de 2018]

GARGallo, B., SUÁREZ, J.M., GARcíA, E., PÉreZ, C. Y SAHUQUiLlo, P.M. (2012). "Enfoques de aprendizaje en estudiantes universitarios excelentes y en estudiantes medios" en Revista española de pedagogía, 252, p. 185-200.

https://revistadepedagogia.org/wp-content/uploads/2012/05/252-01.pdf [Consulta: 21 de marzo de 2019]

HERNÁNDEZ, A. y CAMARGO, A. (2017). "Autorregulación del aprendizaje en la educación superior en Iberoamérica: una revisión sistemática" en Revista latinoamericana de psicología, vol 49, issue 2, p. 146-160.

https://doi.org/10.1016/j.rlp.2017.01.001 [Consulta : 20 de marzo de 2019]

LABUHN, A.S., ZIMMERMAN, B.J. y HASSELHORN, M. (2010). "Enhancing students' selfregulation and mathematics performance: the influence of feedback and self-evaluative standards " en Metacognition Learning, vol. 5, issue 2, p. 173-194.

https://doi.org/10.1007/s11409-010-9056-2 [Consulta : 20 de marzo de 2019]

LLORENS, A.C., VIDAL-ABARCA, E. y CERDÁN, R. (2016). "Formative feedback to transfer selfregulation of task-oriented reading strategies " en Journal of Computer Assisted Learning, vol. 32, p. 314-331.

https://doi.org/10.1111/jcal.12134 [Consulta : 27 de febrero de 2019]

PANADERO, E y ALONSO-TAPIA, J. (2014). "Teorías de autorregulación educativa: una comparación y reflexión teórica" en Psicología Educativa, vol 20, issue 1, p. 11-22.

$<$ doi: 10.1016/j.pse.2014.05.002> [Consulta : 27 de febrero de 2019]

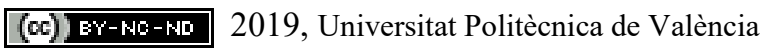


Comienzo de los alumnos en la Universidad: autorregulación y primeros resultados

TORRE, J.C. (2006). La autoeficacia, la autorregulación y los enfoques de aprendizaje en estudiantes universitarios. Madrid: Universidad Pontificia de Comillas (tesis doctoral).

TORRE, J.C. (2007). Una triple alianza para un aprendizaje universitario de calidad. Madrid: Universidad Pontificia de Comillas.

https://ebookcentral.proquest.com/lib/bibliotecaupves-ebooks/detail.action?docID=3196432

[Consulta : 10 de enero de 2019]

(c) Br-NC-ND 2019, Universitat Politècnica de València 